\title{
O Projeto EMAI: uma Análise de sua Estrutura Organizacional e seus Pressupostos Metodológicos
}

\section{The EMAI Project: an Analysis of its Organizational Structure and its Methodological Assumptions}

\author{
Augusta Teresa Barbosa Severino*a, Renata Cristina Geromel Meneghetti ${ }^{\mathrm{b}}$ \\ ${ }^{a}$ Universidade Estadual Paulista.Programa de Pós-graduação em Educação para a Ciência. SP, Brasil. \\ bUniversidade de São Paulo. Instituto de Ciências Matemáticas e de Computação. SP, Brasil. \\ *E-mail: gutasix@yahoo.com.br
}

\begin{abstract}
Resumo
Este artigo focaliza o projeto EMAI (Educação Matemática nos anos iniciais) criado em 2013 pelo Governo do Estado de São Paulo e implementado nas escolas no ano de 2014 e tem como propósito analisar a estrutura organizacional e os pressupostos metodológicos deste material na versão destinada ao uso do professor, buscando responder à seguinte questão de investigação: O projeto EMAI dá ao professor um suporte pedagógico que propicie a autonomia e a reflexão sobre sua própria prática pedagógica? Para tal, além dos aspectos gerais do material foi também considerado o tratamento dado ao conhecimento matemático, ou seja, as orientações didático-pedagógicas deste material no que se refere ao processo de ensino e aprendizagem de matemática. A investigação caracteriza-se como qualitativa e foi efetuada com base em análise documental, compreendendo as três seguintes fases: (i) análise da estrutura do material e das orientações pedagógicas gerais; (ii) análise das sugestões apresentadas para o desenvolvimento de um conteúdo específico; e (iii) considerações finais a respeito desta análise. Ao final desse processo foi possível apontar que o material, apesar de limitar a autonomia do professor, mostra-se como um recurso que auxilia seu trabalho e estudos paralelos por trazer questões relativas ao ensino de matemática que, na maioria das vezes, é um obstáculo para o professor dos anos iniciais da Educação Básica.
\end{abstract}

Palavras-chave: Projeto EMAI. Ensino e Aprendizagem de Matemática. Autonomia. Formação de Professores. Orientações DidáticoPedagógicas.

\section{Abstract}

This article focuses on the EMAI project (Mathematics Education in the initial years) created in 2013 by the Government of the State of São Paulo and implemented in schools in the year 2014 and its purpose is to analyze the organizational structure and the methodological assumptions of this material in the version destined to use the teacher, seeking to answer the following research question: Does the EMAI project give the teacher a pedagogical support that fosters autonomy and reflection on his own pedagogical practice? For this, in addition to the general aspects of the material was also considered the treatment given to the mathematical knowledge, that is, the didactic-pedagogical orientations of this material with regard to the teaching and learning process of mathematics. The research is characterized as qualitative and was carried out based on documentary analysis, comprising the following three phases: (i) analysis of the structure of the material and the general pedagogical guidelines; (ii) analysis of the suggestions presented for the development of specific content; and (iii) final considerations regarding this analysis. At the end of this process it was possible to point out that the material, although limiting the autonomy of the teacher, is shown as a resource that helps his work and parallel studies to bring about issues related to mathematics teaching that, in most cases, is an obstacle for the teacher of the initial years of Basic Education.

Keywords: EMAI Project. Teaching and Learning of Mathematics. Autonomy. Teacher education. Didactic-Pedagogical Guidelines.

\section{Introdução}

O presente artigo é um recorte da dissertação de mestrado intitulada "O projeto EMAI: uma análise sobre seus pressupostos políticos, filosóficos e pedagógicos e a questão da autonomia" que teve como objetivo discutir a questão da autonomia para os professores que trabalham com o material EMAI (Educação Matemática nos anos iniciais), de modo a tentar compreender se essa autonomia estaria indicada no discurso do material e na fala dos educadores (professores e coordenadora pedagógica), bem como, tentar entender até que ponto a formação inicial e continuada interferem na percepção e reflexão sobre essa autonomia.

A partir da análise da versão destinada ao professor $\left(4^{\circ}\right.$ ano) foram evidenciados os aspectos gerais do material e também o tratamento dado ao conhecimento matemático, ou seja, as orientações didático-pedagógicas apresentadas referentes ao ensino e a aprendizagem de matemática.

O projeto EMAI foi criado em 2013 pelo Governo do Estado de São Paulo, porém foi efetivamente implantado no ano de 2014 nas escolas de $1^{\circ}$ ao $5^{\circ}$ ano da Educação Básica, contando com material impresso em forma de livros, divididos em dois volumes, um destinado ao professor e outro para uso dos alunos e contemplando o conteúdo matemático dos dois semestres, numa estrutura organizacional de divisão do conteúdo que ainda se mantém.

Paralela à implantação do material, a Diretoria de Ensino ofereceu aos Professores Coordenadores de cada unidade escolar um curso preparatório para que repassassem aos professores, nos horários de ATPC (aulas de trabalho 
pedagógico paralelo), aquilo que estudavam. No caso específico da unidade escolar apresentada na dissertação, o curso de formação para os professores acontecia às quintasfeiras, desde 2014, no horário das $17 \mathrm{~h}$ às $19 \mathrm{~h}$ e, a partir do ano de 2017, às quartas-feiras no mesmo horário.

Para tal, apontou-se a necessidade de uma análise crítica sobre o texto que sustenta o material partindo de um breve contexto histórico, uma análise do conteúdo do material em si e finalmente apontando algumas considerações das autoras quanto à questão da autonomia docente frente às imposições ideológicas presentes no texto que dá suporte ao material.

A análise foi efetuada buscando responder a seguinte questão de investigação: O projeto EMAI dá ao professor um suporte pedagógico que propicie a autonomia e reflexão sobre sua própria prática pedagógica?

Em relação a esta questão faz-se necessário esclarecermos que o termo autonomia está relacionado com independência, liberdade ou autossuficiência. Neste trabalho compreendemos a autonomia do professor podendo se referir à autonomia real ou à autonomia relativa, no sentido posto por Severino (2016, p.72)

autonomia real, entende-se uma autonomia completa que dá ao professor a oportunidade de participação efetivamente de todas as etapas do ensino. Já a autonomia relativa poderia, por exemplo, apontar os direcionamentos para o professor seguir, portanto, uma autonomia relativa, subordinada a um grupo maior que decide e comanda suas ações durante a execução das atividades.

Assim, no que segue, apresentaremos o referencial teórico que dá sustento a esta investigação. Na sequência procederemos à análise do material EMAI e por fim traçaremos as considerações finais.

\section{Algumas Considerações Teóricas}

Tratar das questões teóricas significa, antes de tudo, apresentar ao leitor a estrutura de pensamento que alicerça as reflexões das autoras. Nesse caso específico apresentaremos, como proposta crítica de reflexão sobre a pesquisa, a Pedagogia Histórico-Crítica (PHC), que propõe uma perspectiva de educação que valoriza, além dos aspectos humanos e culturais, também os aspectos sociais e econômicos. Além disso, traz como ponto central o ensino e a aprendizagem dos conteúdos clássicos, historicamente acumulados pelo homem como possibilidade de ascensão cultural das massas trabalhadoras.

Para Saviani (2003, p. 93) pensar a educação do ponto de vista da PHC envolve:

a necessidade de se compreender a educação no seu desenvolvimento histórico-objetivo e, por consequência, a possibilidade de se articular uma proposta pedagógica cujo ponto de referência, cujo compromisso, seja a transformação da sociedade e não sua manutenção, a sua perpetuação. Este é o sentido básico da expressão pedagogia histórico-crítica. Seus pressupostos, portanto, são os da concepção dialética da história. Isso envolve a possibilidade de se compreender a educação escolar tal como ela se manifesta no presente, mas entendida esta manifestação presente como resultado de um longo processo de transformação histórica.

A partir dessa perspectiva é possível pensar na questão do ensino e da aprendizagem da matemática e em seus conteúdos essenciais e variados, trazendo à tona desde a abstração matemática até a apropriação de conteúdos científicos e tecnológicos, passando pelo domínio da linguagem oral e escrita. Há, portanto, segundo Saviani (2003), a necessidade de uma forma de apreensão cognitiva que valorize o conhecimento inicial do aprendiz, como ponto de partida para um longo processo de apropriação desses conteúdos historicamente acumulados, a serem ensinados pelo professor.

Nessa perspectiva, referente ao projeto EMAI questionamos: como pensar no conhecimento do aluno como ponto de partida, se o ponto de partida já está proposto pelo material? Esse é o primeiro aspecto a ser evidenciado como sendo contrário a uma pedagogia crítica que busca a transformação social por meio da participação efetiva da educação.

Assume-se aqui, portanto, a PHC, como uma concepção crítica de educação como ponto de partida e de chegada, tanto para o professor quanto para os alunos, por meio da superação da visão excludente e alienante que muitos têm da educação escolar e do apreço ao material didático como "salvador" da educação. Fundamentada no materialismo histórico-dialético, a PHC traz uma visão crítica de homem, de sociedade e, principalmente, do papel atribuído à escola e aos educadores.

Sabe-se que a educação é um fenômeno próprio dos seres humanos. Assim sendo, a compreensão da natureza da educação passa pela compreensão da natureza humana. Ora, o que diferencia os homens dos demais fenômenos, o que o diferencia dos demais seres vivos, o que o diferencia dos outros animais? ... é o trabalho. Dizer, pois, que a educação é um fenômeno próprio dos seres humanos significa afirmar que ela é, ao mesmo tempo, uma exigência do e para o processo de trabalho, bem como é, ela própria, um processo de trabalho. (Saviani, 2003, p.11-12).

O homem constitui-se, portanto, nas relações que estabelece com o trabalho e com a educação, que é por si mesma um processo de trabalho. Assim, as discussões que surgem a partir desse posicionamento crítico, apontam para um novo olhar sobre os pontos fundamentais dentro da escola: currículo, formação de professores e processos de ensino e aprendizagem, em que os professores têm papel fundamental na emancipação dos trabalhadores, por meio do domínio crítico dos conteúdos, do acesso ao saber sistematizado que lhes fora historicamente negado. Para Saviani (2005, p.31), o educador crítico tem em mãos:

uma arma de luta capaz de permitir-lhes o exercício de um poder real, ainda que limitado. Lutar contra a marginalidade por meio da escola significa engajar-se no esforço para garantir aos trabalhadores um ensino da melhor qualidade possível nas condições históricas atuais.

É, pois, um esforço contínuo que encontra inúmeras barreiras nas condições históricas atuais com as quais o professor crítico se depara cotidianamente. São currículos, 
materiais e metodologias impostas ao professor que, sem uma formação adequada para a autonomia nas escolhas e meios para argumentar, acaba assumindo isso tudo como forma de salvar os alunos do caos, mas acaba colocando-os ainda mais na posição de marginalizados do sistema, o que não permitirá que se quebre o ciclo: professores malformados, escola como depósito de alunos, conteúdos vazios e sociedade facilmente manipulável.

Desse modo, o ato de ensinar precisa ser fundamentado na valorização do conteúdo como instrumento de luta, pois é por meio dele que haverá discussão e reflexão sobre a prática social no sentido do avanço do pensamento sincrético, desorganizado e fundamentado no senso comum para um pensamento sintético, organizado, acerca dos aspectos econômicos, políticos e filosóficos que sustentam a sociedade que o cerca e que o empurra para o abismo da marginalização social.

Freire (2016, p.101) afirma que não se pode desconsiderar os ideais revolucionários dos professores e alunos para o movimento de avanço educacional quando se pensa a partir de um posicionamento crítico.

Educador e educandos (liderança e massas), cointencionados à realidade, se encontram numa tarefa em que ambos são sujeitos no ato, não só de desvelála e, assim, criticamente conhecê-la, mas também no de recriar este conhecimento. Ao alcançarem, na reflexão e na ação em comum, este saber da realidade, se descobrem como seus refazedores permanentes. Deste modo, a presença dos oprimidos na busca de libertação, mais que pseudoparticipação, é o que deve ser: engajamento.

Mas como realmente engajar-se, se a discussão está centrada apenas na resolução das atividades propostas no material?

A luta por uma educação crítica exige, portanto, a busca constante pela libertação das amarras ideológicas do capital, consequentemente pressupõe-se a existência de um processo educativo que vise à reflexão sobre todos os condicionantes sociais que disseminam a ideologia dominante, inclusive os materiais prontos como proposta curricular.

\subsection{Ideologia Dominante x Transformação Social}

Para Severino e Meneghetti (2014) as relações da criança com o mundo exterior começam a se ampliar a partir do momento que saem do âmbito familiar, pois surgem novas formas de relacionamento, em especial, na escola, elo entre a criança e a sociedade e, mais profundamente, entre a criança e o conhecimento sistematizado.

A escola, por seu poder essencialmente formador, influencia atitudes e dissemina ideologias, que estão imbricadas na essência de cada professor e de cada linha filosófica que compõe plano de ensino e projeto pedagógico. Para Pêcheux (1988), a ideologia fornece evidências que estão imbricadas na fala, na palavra ou em um enunciado que se queira dizer, mascarando o caráter material do sentido dessas falas.
Há, portanto, uma materialidade naquilo que se diz e que se faz; e que pode firmar, em sua força formadora, a ideia de que a ideologia dominante seja reproduzida e validada pelas esferas sociais, dentre elas a escola, transformando também as relações de produção do próprio saber que, por ser social, deve ser de todos. Entretanto, a elaboração do saber está restrita àqueles que dominam os instrumentos de apropriação e reflexão sobre os aspectos sociais, econômicos e culturais que compõem a sociedade e a história.

Entende-se que há uma ideologia opressora que realiza a mediação entre a estrutura social e o sujeito, que pode ser disseminada de modo efetivo através da escola. Entretanto, não se pode evidenciar, numa perspectiva crítica de educação, o fatalismo imposto à educação escolar, por uma crítica que desconsidera a possibilidade do papel transformador da escola, caracterizando-a unicamente como reprodutora do sistema que designa as camadas menos favorecidas da sociedade ao trabalho exclusivamente material e não intelectual.

Há uma profundidade no sentido e na função da escola quando considerada um importante instrumento de elevação cultural e apropriação do saber sistematizado. É por isso que a atuação do professor crítico se faz necessária ao disponibilizar ao aluno, também de maneira crítica, os instrumentos para que se aproprie do conhecimento, por meio dos conteúdos historicamente acumulados; e possa refletir sobre os objetos de conhecimento e por meio deles interpretar o mundo que o cerca em todas as suas nuances: social, econômica e cultural.

Além dessa valorização da escola como um dos principais pontos de transformação social também é preciso esclarecer que a opção aqui pela valorização dos conteúdos sistematizados não significa, uma proposta de retorno ao estudo passivo e acrítico, tal como feito no ensino tradicional, em que o ensino é alicerçado no autoritarismo do professor e aprendizagem passiva. Segundo Fiorentini (1995, p.15),

a escola, como parte desse sistema, teria uma função importante para sua manutenção e estabilidade. Mais especificamente: a educação escolar teria a finalidade de preparar e 'integrar' o indivíduo à sociedade, tornando-o capaz e útil ao sistema.

$\mathrm{Na}$ verdade, para a $\mathrm{PHC}$, se faz necessário refletir sobre o papel social da escola e a importância que ela tem na construção do ser social, não como um ser passivo, mas como aquele que compreende e se relaciona dinamicamente com o conhecimento.

Para Saviani (2003) possibilitar o acesso de todos ao mundo do saber sistematizado é papel da escola, que precisa estar organizada, disponibilizando formas adequadas de acesso ao saber elaborado, ao saber metódico e científico.

Trata-se de se apropriar do conhecimento, do saber elaborado que é produzido socialmente por meio de um processo de troca e reflexão que se inicia desde os primeiros anos de escolaridade, em especial na relação entre professor, aluno e objeto de estudo. É importante que haja o domínio dos instrumentos de elaboração e sistematização do saber e isso só 
pode ser feito através da escola.

Para Paulo Freire (1996, p.25), professores e alunos, mesmo que diferentes em termos de saber sistematizado, crescem juntos nesse processo de apropriação do conhecimento, pois discutem, elaboram e reestruturam não como objetos um do outro, mas como parceiros em busca do crescimento pelo conhecimento dos instrumentos, dos objetos de estudo, este sim passível de ser dominado.

É nesse sentido que ensinar não é transferir conhecimentos, conteúdos, nem formar é ação pela qual um sujeito criador dá forma, estilo ou alma a um corpo indeciso e acomodado. Não há docência sem discência, as duas se explicam e seus sujeitos, apesar das diferenças que os conotam, não se reduzem à condição de objeto, um do outro.

É uma educação que enfatiza o processo de ensino e aprendizagem, reconhece o meio social como aspecto fundamental do desenvolvimento humano e que, portanto, exige um intenso processo de reflexão crítica. Para Saviani (2002), o automatismo está imbricado no domínio desses instrumentos, pressupostos para a liberdade, pois não é possível ser criativo e crítico sem dominar determinados mecanismos.

Isso porque, uma visão simplista e limitada de educação não permite a reflexão crítica e criativa sobre o mundo, pois coloca em segundo plano a apropriação do saber sistematizado. Quando se pensa especificamente no ensino de matemática é possível evidenciar que, muitas vezes, o conhecimento cotidiano, o conhecimento básico dos conceitos é colocado como superior ao conhecimento sistematizado, sendo que, este saber cotidiano deveria ser o ponto de partida para o trabalho em sala de aula e não a principal meta do trabalho docente.

Os conteúdos são fundamentais e sem conteúdos relevantes conteúdos significativos, a aprendizagem deixa de existir, ela transforma-se num arremedo, ela transformase numa farsa. Parece-me, pois, fundamental que se entenda isso e que, no interior da escola, nós atuemos segundo essa máxima: a prioridade de conteúdos, que é a única forma de lutar contra a farsa do ensino ... porque o domínio da cultura constitui instrumento indispensável para a participação política das massas... Então, dominar o que os dominantes dominam é condição de libertação. (Saviani, 2005, p. 55).

Defende-se aqui, portanto, a importância de uma reflexão crítica acercados condicionantes pedagógicos que alicerçam o ensino, em especial da matemática, por meio da análise do projeto EMAI que traz a premissa da inovação dos processos de ensino e aprendizagem. Para Gregolin (2006, p.102), analisar o material é válido, pois:

analisar a autoria na relação que o texto estabelece com o sujeito que o produziu significa conceber o sujeito da escrita como uma construção do próprio discurso. Não se trata, portanto, do sujeito empírico, nem do sujeito enquanto indivíduo. Esse 'sujeito do discurso' está inscrito na materialidade do texto, na maneira como ele aponta para seu autor.

Isso, porque, tornou-se fundamental a análise acerca de todos os movimentos do processo educativo, desde o material oferecido até a prática propriamente dita, estabelecida na proposta didática. Uma estrutura fixa que determina todas as etapas da aula em que o professor orienta a execução das atividades. Entretanto, na perspectiva da $\mathrm{PHC}$, o fato de o aluno estar sendo orientado a cumprir determinada atividade não se caracteriza como ensino.

Temos, pois, hoje, já bastante difundida a seguinte situação: professores que não ensinam, educadores que não educam. Essa situação é muitas vezes justificada a partir da ideia de que educação é autoeducação; é o educando que se educa, o professor é um facilitador da educação - ele está aí, e o que o educando pedir, ele faz. Ora, essa é uma posição que considero omissa e que só serve aos interesses dominantes. Porque, se se trata de tomar uma posição clara em relação a utilizar a escola como um instrumento de participação efetiva das massas, então o professor não pode se omitir da tarefa de ensinar, de instruir. (Saviani, 2002, p. 188)

Assim, para que se compreenda melhor a ideia defendida aqui de que a participação efetiva do professor na elaboração, execução e análise de todas as etapas do ensino e da aprendizagem é o ponto central do que se entende por autonomia real, há a necessidade de entender o tratamento dado pelo material EMAI às questões referentes ao ensino e à aprendizagem da matemática nos anos iniciais da Educação Básica, bem como sua estrutura organizacional e as orientações pedagógicas, para perceber as nuances referentes à questão da autonomia docente.

No que segue, serão apresentados os processos de análise e reflexão sobre o material EMAI, evidenciando, a partir de uma visão crítica de educação, os limites de sua estrutura organizacional e de suas sequências didático-pedagógicas previamente estabelecidas.

\section{Material e Métodos}

Optou-se, nessa pesquisa pelo trabalho qualitativo. Nessa abordagem, evidenciam-se pormenores relativos a pessoas e locais que precisaram ser considerados numa complexa rede de relações que envolveram contexto e indivíduos diante do material, foco dessa análise.

Segundo Bogdan e Biklen (1994, p. 16) é possível afirmar que, neste tipo de abordagem, as questões que serão investigadas "não se estabelecem mediante a operacionalização de variáveis, sendo, outrossim, formuladas com o objetivo de investigar os fenômenos em toda a sua complexidade e em contexto natural".

Nessa perspectiva, procedeu-se à análise geral do material como um todo (constituído de 5 livros do $1^{\circ}$ ao $5^{\circ}$ ano da Educação Básica) e escolheu-se um ano específico para se fazer uma análise mais detalhada. $\mathrm{Na}$ parte específica, optamos por analisar o material do $4^{\circ}$ ano, por ser o ano em que a pesquisadora, primeira autora deste artigo, estava atuando durante a investigação. A partir desta escolha, buscouse evidenciar, por meio do estudo minucioso dos textos que antecedem as atividades, da estrutura organizacional e dos 
pressupostos metodológicos, se haveria a possibilidade de responder à questão estabelecida no início da proposta.

Desse modo, os textos serão considerados aqui como parte do discurso dos idealizadores para defesa do material. Para Foucault (como citado em Gregolin, 2006, p. 135) são discursos que estão submetidos:

a um jogo de prescrições que determinam exclusões e escolhas; nesse sentido elas não são, pura e simplesmente, modos de fabricação de discursos, pois são definidas por instituições (técnicas, jurídicas, escolares, etc.) que ao mesmo tempo as impõem e as mantêm.

Entende-se que tais discursos sofrem exclusões e escolhas de certas práticas e teorias que são determinadas e que também determinam a vontade do saber de quem diz/ escreve, sendo alicerçadas por um sentido ideológico e por uma lógica imbuída de materialidade que é, pois, histórica e profundamente tendenciosa.

Essa materialidade dos discursos está imbricada de uma teia de relações sociais tão complexas que exigiu uma análise que considerasse os seguintes aspectos: (i) análise da estrutura do material e das orientações pedagógicas gerais; (ii) análise detalhada das sugestões apresentadas para o desenvolvimento de um conteúdo específico para exemplificar; e (iii) considerações finais a respeito desta análise.

\section{Análise do Material}

$\mathrm{Na}$ página de abertura do material, destinada especificamente ao professor, há uma carta escrita pelo Secretário da Educação do Estado de São Paulo no período da implantação do material em 2013, na qual busca explicar o intuito da criação deste material que, segundo ele, começou a ser idealizado em 2012 como um dos projetos para o trabalho com a matemática e ampliação do Programa Ler e Escrever, a serem desenvolvidos no âmbito da Coordenadoria de Gestão da Educação Básica (CGEB).

O documento define que a implantação desse projeto será de suma importância, pois "amplia a abrangência e proporciona oportunidade de trabalho sistemático nesta disciplina”. Isso, porque, o projeto EMAI foi criado para "articular o processo de desenvolvimento curricular em matemática, a formação de professores e a avaliação, elementos-chave de promoção da qualidade da educação" (São Paulo, 2013, p. 3).

A partir do entendimento dessa proposta inicial é possível destacar os três focos de discussão do material que centralizam as reflexões acerca do contexto educacional: currículo; formação de professores e alunos; e avaliação.

Percebe-se que a ideia inicial do projeto EMAI é orientar o professor, em processo de formação, a seguir e/ ou executar as atividades do material e ainda utilizá-lo como fonte de estudos, reflexões e discussões entre docentes e coordenação pedagógica. O que se questiona nesse ponto é: De que maneira o currículo pronto, com todos os processos de desenvolvimento de cada atividade já previstos, auxiliam nesse processo de formação de professores?

Há, pois, um choque de duas realidades nessa análise: a proposta de uma pedagogia crítica de educação que exige que o professor participe dos três momentos de reflexão (currículo, formação e avaliação); e a proposta de um projeto que apresenta os momentos prontos para que o professor execute as atividades e seja por elas formado para o trabalho com a matemática.

Para o desenvolvimento das atividades, o material traz, como alicerce teórico, as Trajetórias Hipotéticas de Aprendizagem (THA), ou seja, apresenta um plano de trabalho centrado na tomada de decisão do professor sobre os processos de ensino e aprendizagem, baseado nas hipóteses dos alunos sobre cada situação proposta em sala de aula. É como um ciclo que avança a partir das ideias do professor acerca das respostas dos alunos para determinada atividade. Há um processo de realização interativa das atividades, aliado ao processo de avaliação que permite o avanço no conhecimento do professor sobre aquilo que os alunos já sabem.

Na Figura é possível identificar como é definido o termo “Trajetórias Hipotéticas de Aprendizagem", a partir da proposta de Martin Simon (1995)

Figura 1- Ciclo de ensino de matemática abreviado

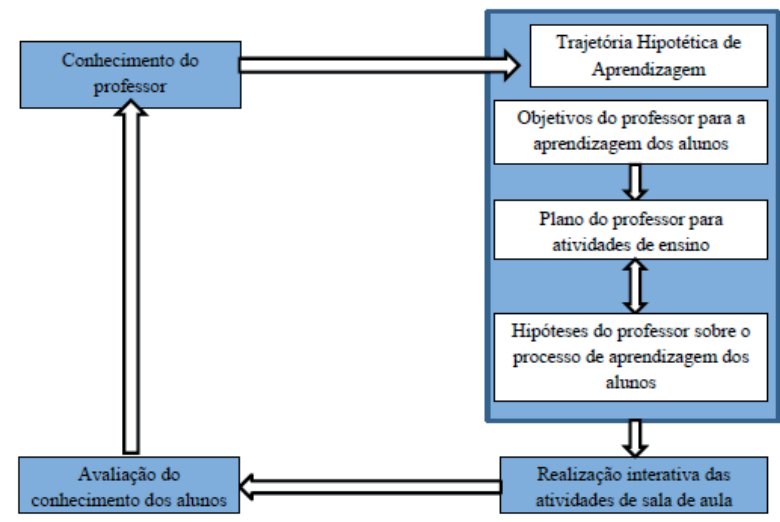

Fonte: Adaptado do Livro 1 do material EMAI 4 ANO, 2014.

É, portanto, o plano de atividades do professor e suas hipóteses sobre o processo de aprendizagem dos alunos que indicarão os objetivos e caminhos a serem seguidos. Há uma interatividade entre professor-atividades-alunos, sendo a avaliação o meio para renovar o conhecimento do professor sobre o que os alunos já sabem. Enfim, é um ciclo ininterrupto de proposta e retomada que traria avanços a todos os envolvidos no processo de ensino e aprendizagem.

Entretanto, ao analisar tal proposta teórica, é possível questionar: como uma teoria baseada nos pressupostos do professor sobre os processos de ensino e aprendizagem pode sustentar o projeto EMAI que propõe uma prática fundamentada na execução de planos prontos, que não partiram do conhecimento do professor sobre seus alunos específicos?

Parece haver uma incoerência entre a teoria e o material 
proposto, entre a criticidade esperada do professor para a tomada de decisão e a proposta apresentada para que ele execute. Isso porque há uma ideia de avaliação contínua pelo professor para que as trajetórias sejam constantemente renovadas por ele e não pelo material. Portanto, tornase fundamental para as THA a avaliação de seus próprios objetivos, planos e hipóteses de aprendizagem para que possa tomar decisões sobre o planejamento da sequência das aulas. Para Hoffmann (2008, p.17) a avaliação é:

uma ação ampla que abrange o cotidiano do fazer pedagógico e cuja energia faz pulsar o planejamento, a proposta pedagógica e a relação entre todos os elementos da ação educativa. Basta pensar que avaliar é agir com base na compreensão do outro, para se entender que ela nutre de forma vigorosa todo o trabalho educativo.

Uma nova questão surge para reflexão: Como avaliar a simples execução de uma atividade que não foi pensada pelo professor para determinada turma? Avalia-se a forma como o aluno executa a atividade e se atendeu aos objetivos e hipóteses traçados pelo material. Na verdade, em uma análise mais crítica, o professor cumpre apenas a tarefa de aplicar a atividade e verificar se os resultados da execução foram satisfatórios ou não. Entretanto, a verificação de uma falha no entendimento dos alunos não garante que haverá, por parte do professor, a retomada do foco da dúvida, que pode não estar prevista no material. É como se a teoria não estivesse vinculada à proposta, não sendo necessária a presença do docente no projeto.

Além disso, as atividades do material do professor apresentam descrição completa da aula a ser seguida, dividida em três momentos de trabalho: Conversa Inicial, Problematização e Observação/Intervenção. Esses momentos, denominados aqui "categorias metodológicas" existem para que o professor possa ter clareza do desenvolvimento da aula, desde o momento de apresentar a atividade aos alunos até a avaliação da mesma e, além disso, são apresentadas as instruções de como intervir na execução das atividades para que atinja as expectativas de aprendizagem propostas. $\mathrm{O}$ sucesso do aluno, portanto, será determinado pela sequência correta da aula pelo professor, a partir dos três momentos apresentados. Onde se encontram, então, as THA que propõem que o professor parta do conhecimento que ele tem sobre a sala, seus objetivos e seus procedimentos?

No desenvolvimento das atividades, as THA estão organizadas em forma de "planos de atividades", com sequências didáticas específicas para cada trajetória (THA). No primeiro plano, por exemplo, são cinco sequências de atividades que visam contemplar os quatro eixos: números e operações, espaço e forma, grandezas e medidas e tratamento da informação; bem como, as expectativas de aprendizagem determinadas para tais atividades. Isso se desenvolve, nos outros planos, com suas sequências didáticas que contemplam sempre esses quatro eixos, com atividades diversificadas em cada sequência.
No que segue, será apresentado um exemplo específico do material que demonstra tais sequências e atividades.

\subsection{Exemplificando com o material do $4^{\circ}$ ano: referente à estrutura organizacional}

Em relação ao aspecto organizacional, ao analisar o material do $4^{\circ}$ ano, identificamos que apenas a primeira THA está dividida, em cinco sequências de atividades que contemplam os quatro eixos do ensino de matemática acima descritos. Já as demais THA estão em apenas quatro sequências, mas que também visam contemplar os quatro eixos. No início de cada uma delas, já estão apresentadas as expectativas de aprendizagem que nortearão todas as atividades a serem desenvolvidas nas aulas.

$\mathrm{Na}$ sequência 1, por exemplo, são apresentadas as seguintes expectativas:

- Reconhecer números naturais no contexto diário.

- Compreender e utilizar as regras do sistema de numeração decimal, para leitura, escrita, comparação e ordenação de números naturais.

Espera-se que, ao cumprir as atividades que vão de 1.1 a 1.5, os alunos tenham atendido às expectativas acima descritas. São atividades em que os alunos deverão "refletir" sobre a utilização dos números no seu cotidiano.

$\mathrm{Na}$ atividade 1.1os alunos devem, em duplas, escrever um pequeno texto sobre as situações em que utilizam números e se esses números indicam contagem, ordem, medida ou código. No final desta atividade, o material apresenta uma definição para o conceito de número natural.

A atividade 1.2 propõe que os alunos individualmente completem uma sequência de cem números entre 500 e 600 , observando as linhas e colunas que indicam grupos de 10 números. Tal atividade pressupõe que todos os alunos conheçam números maiores que 500 no $4^{\circ}$ ano, deixando de considerar uma turma, por exemplo, em que a maioria dos alunos tenha dificuldades de aprendizagem.

$\mathrm{Na}$ atividade 1.3 os alunos devem calcular quantidades individualmente, fazendo agrupamentos ( 8 grupos de 10, mais 5) e completar as sequências numéricas que correspondem à quantidade de "cards" de cada criança do problema, identificando antecessores e sucessores das sequências numéricas.

$\mathrm{Na}$ atividade 1.4 os alunos devem confeccionar individualmente cartelas de um jogo sobre: "Antecessor e Sucessor", em que, cada jogador deve identificar na cartela apresentada por seu oponente, o antecessor e o sucessor correspondentes. Ganha quem acertar mais números. Depois de várias rodadas, os alunos devem, individualmente, resolveras questões propostas sobre o assunto.

$\mathrm{Na}$ atividade 1.5, os alunos devem compor com algarismos os números propostos que estão escritos por extenso, utilizando fichas com números a partir dos conceitos de unidade, dezena e centena. Por exemplo: que fichas devem ser utilizadas para compor o número novecentos e três. Essas fichas se encontram 
no anexo de cada material do aluno. Em seguida, deverão formar números maiores, que envolvem a ordem da unidade de milhar. Assim, são finalizadas as atividades da primeira sequência.

Os alunos, então, iniciarão a segunda sequência de atividades que contemplam a seguinte expectativa:

- Compreender e utilizar as regras do sistema de numeração decimal, para leitura, escrita, comparação e ordenação de números naturais.

É possível perceber, desse modo, que as atividades vão seguindo de modo a vencer as expectativas pré-determinadas de acordo com os eixos: números e operações, espaço e forma, grandezas e medidas e tratamento da informação. Por exemplo, na sequência três, as expectativas de aprendizagem são:

- Reconhecer semelhanças e diferenças entre corpos redondos e poliedros.

- Identificar planificações de corpos redondos e poliedros.

Assim, seguem-se sucessivamente as sequências de atividades de acordo com as expectativas propostas para cada THA. No primeiro livro são: quatro THA com as sequências de atividades de 01 a 17; e no segundo livro são: quatro THA com as sequências de atividades de 18 a 33.

No que segue a fim de se compreender melhor o tratamento dado ao conhecimento matemático e seu ensino e aprendizagem, será apresentada uma das unidades do material, enfatizando a questão da autonomia docente como ponto de partida para a análise e reflexão.

\subsection{Análise quanto ao que há de específico na unidade 1 do material EMAI: expectativas e "categorias metodológicas"}

No início de cada unidade, o material apresenta as expectativas de aprendizagem que se pretende alcançar. No caso específico da unidade 1 do material do $4^{\circ}$ ano é apresentado um quadro contendo os quatro eixos do ensino de Matemática e suas respectivas expectativas, conforme Quadro 1.

Quadro 1 - Expectativas de aprendizagem por eixos

\begin{tabular}{|c|c|}
\hline $\begin{array}{l}\text { Números e } \\
\text { Operações }\end{array}$ & $\begin{array}{l}\text { 1. Reconhecer números naturais no contexto } \\
\text { diário. } \\
\text { 2. Compreender e utilizar as regras do sistema } \\
\text { de numeração decimal, para leitura, escrita, } \\
\text { comparação e ordenação de números naturais. } \\
\text { 3. Analisar, interpretar e resolver situações- } \\
\text { problema, compreendendo diferentes significados } \\
\text { das operações do campo aditivo. } \\
\text { 4. Calcular o resultado de adições e subtrações } \\
\text { com números naturais, por meio de estratégias } \\
\text { pessoais e por cálculos aproximados realizados } \\
\text { por estimativa e arredondamento de números } \\
\text { naturais (pelo uso de técnicas operatórias } \\
\text { convencionais). } \\
\text { 5. Dominar estratégias de verificação e controle } \\
\text { de resultados pelo uso do cálculo mental. }\end{array}$ \\
\hline
\end{tabular}

...continuação.

\begin{tabular}{|c|l|}
\hline $\begin{array}{c}\text { Espaço e } \\
\text { Forma }\end{array}$ & $\begin{array}{l}\text { 1. Reconhecer semelhanças e diferenças entre } \\
\text { corpos redondos e poliedros. } \\
\text { 2. Identificar planificações de corpos redondos e } \\
\text { de poliedros. }\end{array}$ \\
\hline $\begin{array}{c}\text { Grandezas e } \\
\text { Medidas }\end{array}$ & $\begin{array}{l}\text { 2. Utilizar unidades de tempo em situações- } \\
\text { problema. } \\
\text { 3. Utilizar medidas de tempo em realizações de } \\
\text { conversões simples, entre dias e semanas, horas } \\
\text { e dias, semanas e meses. }\end{array}$ \\
\hline $\begin{array}{c}\text { Tratamento } \\
\text { da } \\
\text { Informação }\end{array}$ & $\begin{array}{l}\text { 1. Ler informações de tempo em diferentes } \\
\text { registros. }\end{array}$ \\
\hline
\end{tabular}

Fonte: Nota. Livro 1 do material EMAI - $4^{\circ}$ ANO, 2014.

A partir da análise dessas expectativas, entendidas aqui como norteadoras daquilo que o professor deve ter como objetivos são apresentados os planos de atividades, que trazem a(s) expectativa(s) determinada(s). Este primeiro plano engloba as sequências um, dois, três, quatro e cinco por meio de propostas atividades que visam atender às expectativas de cada sequência. Todas são compostas por três etapas preparatórias, as "categorias metodológicas", dispostas em cada atividade e determinam a preparação e o desenvolvimento das aulas.

Estas categorias exigem que o professor visualize a sequência das aulas, tendo clareza de sua ação para que a atividade seja realizada de acordo com as expectativas propostas. Na categoria 1 (“Conversa Inicial”), há sempre uma indicação de como o professor deve iniciar o diálogo com as crianças, tentando fazer com que elas falem sobre o que já conhecem do assunto tratado. É um processo, ao nosso ver, de suma importância para o levantamento das hipóteses iniciais dos alunos.

$\mathrm{Na}$ categoria 2 ("Problematização"), há um encaminhamento contendo perguntas que o professor deve fazer aos alunos para que pensem sobre os conceitos que serão abordados e apresentem respostas a partir de suas próprias vivências cotidianas.

A terceira categoria (“Observação/Intervenção”) orienta o professor a observar a realização da atividade e discutir com os alunos seu processo de resolução do problema, incentivandoos a refletirem sobre situações cotidianas em que utilizariam aqueles conceitos, ou seja, conceitos matemáticos e suas funções sociais.

Vale salientar que as três categorias aparecem em todas as atividades dos dois livros do projeto EMAI que são exclusivos dos conteúdos matemáticos e serão trabalhados durante todo o ano letivo, para orientar o professor e determinar a condução das aulas. O professor assume, portanto, o papel de executor do que lhe é determinado, pois com uma possível formação deficitária não conseguirá se desvencilhar do material didático como seu único suporte, que, por ser imposto, tornar-se-á confiável, como: meta, atividade e fonte de estudo.

Em relação ao desenvolvimento das sequências no qual o material está estruturado, cada sequência pode ser trabalhada 
em uma semana, podendo ser ampliada ou não de acordo com as necessidades da turma. Isso mostra certa abertura do material para a verificação das dificuldades e possíveis avanços na instrumentalização matemática das expectativas propostas, já que também permite que o professor utilize outros materiais para complementar o trabalho.

Individualmente e nas reuniões com seus colegas, além do material sugerido, analise as propostas do livro didático adotado em sua escola e outros materiais que você considerar interessantes. Prepare e selecione as atividades que complementem o trabalho com os alunos. Escolha atividades que precisam ser feitas em sala de aula e as que podem ser propostas como lição de casa (São Paulo, 2013, p. 7).

A proposta de utilização de outros materiais, como os livros didáticos, por exemplo, parte, segundo o EMAI, da necessidade de complementar aquilo que foi evidenciado como dificuldade na execução das atividades propostas e não pela percepção do professor sobre sua aula e suas atividades. Tem-se, assim, a ideia da existência de autonomia do professor, apontada como essa possibilidade de escolha do material que complementará o projeto EMAI. Entretanto, sobre este aspecto questiona-se: a autonomia se limita à sequência proposta pelo projeto? O professor só escolhe aquilo que o completa? Não seria o professor capaz de elaborar e propor suas próprias atividades como seria de fato o aspecto central de uma THA?

Dessa maneira, identifica-se nesse material uma dependência do professor à sequência didática proposta no material e, portanto, ao próprio material. Nesse sentido, há uma autonomia relativa, dando ao professor a ideia de uma autonomia real, enquanto aquele que pensa, executa e avalia a própria prática docente.

Apesar de todos esses pontos negativos do material, ao nosso ver, é preciso reconhecer também elementos positivos, considerados de suma importância: o trabalho em grupo e a conversa inicial. Isso porque permitem a ampliação do relacionamento entre os pares e com o professor, o respeito pelo outro e também a manifestação de opiniões diante daquilo que é proposto. Tais aspectos permitem uma visão mais ampla de um cotidiano escolar e a participação do aluno em momentos valiosos de exposição de ideias, apontamentos e posicionamentos pessoais.

Outro aspecto a ser considerado é que o material sugere que o professor não antecipe informações aos alunos para que eles criem suas próprias estratégias de resolução da atividade, pois é importante incentivá-los a "apresentarem suas formas de solução de problemas, seus procedimentos pessoais" (São Paulo, 2013, p.8). Isso mostra um avanço nos processos de aprendizagem dos alunos, que precisam aprender a ter autonomia no desenvolvimento do pensamento matemático.

O material sustenta a premissa de que os processos de ensino e aprendizagem devem partir dos conhecimentos prévios dos alunos, uma vez que, a criança já sabe certas convenções sociais ao entrar na escola, como, por exemplo, no caso da matemática: medidas, ordem numérica, códigos, entre outros.

Entretanto, esses conhecimentos precisam, necessariamente, ser encarados como ponto de partida a serem explorados, ampliados ou substituídos por um conhecimento sistematizado, organizado, sincrético. E isso só será possível por meio dos conteúdos que serão trabalhados em sala de aula e pelo desenvolvimento da aula pelo professor. Assim, baseando-se nas vivências das crianças como início do processo, o professor tem em mãos a fonte para o planejamento das atividades diversificadas que instrumentalizarão os alunos para que saiam desse conhecimento de senso comum e avancem para o domínio do conhecimento sistematizado.

Mas, que planejamento há quando o material está pronto e com todos os momentos da aula previamente estabelecidos?

$\mathrm{Na}$ verdade, a fundamentação para a preparação das aulas do professor deveria ser sua formação acadêmica aliada à sua prática docente, construída no decorrer de suas atividades. Saviani (2003, p.107-108) defende a importância de uma prática educativa fundamentada no estudo, numa teoria que embase o que se pretende em sala de aula.

Quando entendemos que a prática será tanto mais coerente e consistente, será tanto mais qualitativa, será tanto mais desenvolvida quanto mais consistente e desenvolvida for a teoria que a embasa, e que uma prática será transformada à medida que exista uma elaboração teórica que justifique a necessidade da sua transformação e que proponha as formas de transformação, estamos pensando a prática a partir da teoria. Mas é preciso também fazer o movimento inverso, ou seja, pensar a teoria a partir da prática, porque se a prática é o fundamento da teoria, seu critério de verdade e sua finalidade, isto significa que o desenvolvimento da teoria depende da prática.

$\mathrm{O}$ ato de planejar a partir da teoria e fazer o caminho inverso para pensar a teoria a partir da prática são de suma importância para avançar no sentido de uma autonomia docente. Entendese, portanto, que é preciso que haja o planejamento das aulas a partir da relação latente entre teoria, prática, estudos e pesquisas, de modo a transformar os momentos de planejar e executar em momentos de reflexão, ação e mudança.

$\mathrm{O}$ ambiente de sala de aula precisa ser propício à apropriação e ao desenvolvimento do conhecimento das crianças, através das problematizações das hipóteses e uso de estratégias de resolução de problemas diversos. "A escola deve ajudar a reconstruir o saber cultural, mas, em vez disso, frequentemente não é mais do que uma outra fonte de ideias confusas e concepções alternativas" (Pozo \& Crespo, 2009, p. 94)

Isso aponta para o fato de que se multiplicam dentro da escola essas concepções impostas por outros agentes exteriores ao ambiente escolar. Entretanto, reconhece-se que para o professor, em especial o Pedagogo, responsável pela educação do $1^{\circ}$ ao $5^{\circ}$ ano, tais imposições, que determinam seu planejamento e atuação profissional, acontecem de maneira acelerada e exagerada, pois está direcionada a uma classe, que 
na maioria das vezes, vem de uma formação inicial precária.

Há ênfase exagerada nos procedimentos de ensino em cursos de formação inicial do Pedagogo em detrimento do domínio dos conceitos, que são fundamentais para a formação integral do professor polivalente, ou seja, trabalhará com todas as disciplinas. Então, o professor encontra-se numa posição muito complicada diante da turma: sabe inúmeros procedimentos para ensinar, mas não domina o conceito científico, o conteúdo a ser ensinado. Isso acaba gerando a dependência ao material didático.

A formação dos professores, por exemplo, tanto a inicial quanto a continuada, pouco tem contribuído para qualificálos para o exercício da docência. Não tendo oportunidade e condições para aprimorar sua formação e não dispondo de outros recursos para desenvolver as práticas da sala de aula, os professores apoiam-se quase exclusivamente nos livros didáticos, que, muitas vezes, são de qualidade insatisfatória (Brasil, 1998, p. 21-22).

Por meio dessa reflexão acerca da precariedade da formação de professores é que se entende a necessidade de materiais didáticos que sejam norteadores do processo de ensino, sem substituir explicações, orientações e intervenções do professor. É preciso evidenciar que o material EMAI tem "boa qualidade material" tanto na versão do aluno quanto na do professor, pois o desenvolvimento do conteúdo possui linguagem adequada, as atividades são claras e o material tem boa qualidade de impressão. Neste sentido, este material atende as exigências, quanto à edição e à impressão de livros didáticos, que se fizeram a partir de 1985 com PNLD (Plano Nacional de Livro Didático).

O novo Plano Nacional do Livro Didático, que entrou em vigor com o advento da Nova República em 1985 procura reintroduzir o livro durável, que possa passar de pai a filho e de irmão a irmão. Isso implica, inicialmente, uma melhor qualidade do material (capa, papel, cor, tipo) da edição (Freitag, Motta, \& Costa, 1987, p. 31).

Entretanto, é preciso evidenciar que a qualidade de um material didático não se restringe somente a esses aspectos, ainda que estas sejam partes constituintes da análise de um material.

Machado (1996) destaca que a qualidade de um material está intrinsecamente ligada à formação do docente que precisa, necessariamente, dar ao aluno a oportunidade de registrar no caderno, especificamente, suas próprias ideias, conceitos e conclusões por meio da explicação do professor, com o auxílio do livro didático e não com a utilização apenas do material didático que pode não ser o melhor veículo de informação para o aluno e de solução de dúvidas.

Dante (1996) também enfatiza que o livro didático, quando bem utilizado, tem um papel fundamental na formação dos alunos. Isso porque, na maioria das vezes, só a explicação do professor não é suficiente para sanar dúvidas e fornecer os conceitos necessários para o avanço cognitivo. $\mathrm{O}$ autor apresenta alguns itens que apontam a importância da utilização, sem abusos, do livro didático, em especial no caso da matemática:

- O professor tem muitos alunos, afazeres e atividades extracurriculares que o impedem de planejar e escrever textos, problemas interessantes e questões desafiadoras, sem ajuda do livro didático;

- A matemática é essencialmente sequencial, um assunto depende do outro, e o livro didático fornece uma ajuda útil para essa abordagem;

- Para professores com formação insuficiente em matemática, um livro didático correto e com enfoque adequado pode ajudar a suprir essa deficiência;

- Muitas escolas são limitadas em recursos como bibliotecas, materiais pedagógicos, equipamento de duplicação, vídeos, computadores, de modo que o livro didático constitui o básico, senão o único recurso didático do professor;

- A aprendizagem da matemática depende do domínio de conceitos e habilidades. O aluno pode melhorar esse domínio resolvendo os problemas, executando as atividades e os exercícios sugeridos pelo livro didático;

- O livro didático de matemática é tão necessário quanto um dicionário ou uma enciclopédia, pois ele contém definições, propriedades, tabelas e explicações, cujas referências são frequentemente feitas pelo professor.

Encontram-se, destacados pelos autores, alguns dos aspectos positivos para a implantação do projeto EMAI, como um material visivelmente de qualidade manipulável e também como um meio de "resgatar" o ensino da matemática, apontando os caminhos a serem seguidos para que se alcance as expectativas determinadas, sem, no entanto, descaracterizar a importância do professor como aquele que ensina e do caderno como lugar de sistematização das aprendizagens.

É importante que a elaboração de estratégias próprias do aluno seja o foco para a resolução de problemas e para a ampliação do que o aluno entende das operações matemáticas, por exemplo. Tais problemas precisam ter, necessariamente, “... sentido para as crianças, que tenham algum vínculo com seu cotidiano" Isso porque: "É uma forma de garantir que compreendam as ações contidas nos enunciados, contribuindo para que ampliem suas ideias a respeito das operações" (São Paulo, 2013, p. 9).

O material enfatiza que os problemas precisam fazer sentido para o aluno, partindo do seu cotidiano, mas questiona-se o seguinte: como um material pronto garante que o problema proposto faça sentido para o aluno?

É preciso evidenciar que o projeto EMAI e os materiais didáticos precisam de adaptações e do uso de outros materiais alternativos que, aliados ao conhecimento do professor, promoverão avanços cognitivos nos alunos. Entretanto, há uma preocupação válida com a questão da formação desse professor que precisará fazer as adaptações necessárias e ainda buscar novos materiais de apoio, pois a falta de informações e conceitos podem gerar um ensino superficial e um repúdio cada vez maior à matemática.

O trabalho precisa acontecer de modo integrado com o estudo do material, para que o trabalho não esteja apenas 
ligado ao ato de preencher o livro, mas possa permitir a criação de estratégias diversificadas para solucionar problemas. É por isso que precisam dominar, ao mesmo tempo, o sistema aritmético e o sistema algébrico, mesmo nas séries iniciais, pois, no que se refere ao pensamento algébrico, está claro que, desde muito cedo, já observam o mundo físico e são capazes de estabelecer relações espaciais com os estudos em sala de aula. Isso também é válido para o estudo do tempo, das medidas e do tratamento da informação, pois são habilidades que se desenvolvem a partir do cotidiano e das relações que estabelecem em cada situação vivenciada.

É preciso destacar que o material ainda apresenta um tópico denominado "Procedimentos importantes para o professor", o qual destaca como o professor deve proceder para estudar o material e planejar adequadamente suas aulas (São Paulo, 2013, p. 10):

- Analise as propostas de atividades sugeridas nas sequências e planeje seu desenvolvimento na rotina semanal.

- Analise as propostas do livro didático escolhido e de outros materiais que você utiliza para consulta. Prepare e selecione as atividades que complementem seu trabalho com os alunos.

- Elabore lições de casa simples e interessantes.

O material trata o planejamento como etapa fundamental para o desenvolvimento adequado das atividades, um ponto positivo e de extrema importância para a organização dos caminhos a serem percorridos durante a aula. Há também uma valorização da lição de casa como etapa importante da aprendizagem e isso colabora para que o aluno adquira procedimentos de estudo.

Apesar dos avanços no sentido proposto pelo material ainda resta uma questão: essa liberdade que o material dá ao professor para selecionar outros materiais de apoio e preparar tarefas caracteriza a autonomia docente?

\section{Conclusão}

Neste artigo tivemos como objetivo analisar a estrutura organizacional e os pressupostos metodológicos do material do Projeto EMAI buscando responder à questão: $\mathrm{O}$ projeto EMAI dá ao professor um suporte pedagógico que propicie a autonomia e a reflexão sobre sua própria prática pedagógica?

Pensar no professor autônomo pressupõe que se observe uma prática que traduza a teoria de uma vida em formação constante. Uma prática que supere as amarras ideológicas que impõem um trabalho engessado e submisso ao material didático, pensado e preparado por aqueles que não estão diante da realidade educacional desse professor específico. Pensar em um professor com uma formação tão avançada em termos conceituais e procedimentais que abarcaria toda a gama de situações didáticas que exijam seu posicionamento e sua exposição de saberes, trazendo para o cenário educacional um professor que planeja, executa e reflete sobre sua prática a partir dos condicionantes sociais, políticos, econômicos e filosóficos que sustentam a sociedade.
Entretanto, essa visão da profissão docente esbarra num gigantesco obstáculo: a formação precária dos professores. É preciso evidenciar que, de certa maneira, o material didático EMAI analisado, traz um ponto positivo para o avanço nos processos de ensino e aprendizagem quando aponta um caminho para a superação da lacuna deixada pela formação deficitária dos professores em matemática, pois não é possível pensar em autonomia sem pensar especificamente na formação do profissional, já que ser autônomo depende necessariamente dos saberes que sustentarão a prática.

Não há como negar que exista preocupação com a qualidade da educação, mas será que o professor e o ato de ensinar são levados em consideração pelo material, mesmo que afirme em seu texto que é o professor o protagonista no desenvolvimento do currículo em sala de aula e da construção das aprendizagens dos alunos?

É preciso evidenciar que, para os professores serem vistos como protagonistas, entre outras coisas, deve haver participação efetiva na construção do currículo e em seu planejamento a partir das THA que foram levantadas por meio de sua própria observação das aulas e atividades. Nesse caso específico, o professor não pode ser considerado como protagonista do ato educativo, uma vez que real protagonista é o material, pois é em torno dele que circulam o professor e os alunos.

Assim, a partir da análise da proposta apresentada pelo material questiona-se: o professor toma decisões? Mas o que dizer das decisões que já vêm prontas?

Para se ter autonomia, professores e alunos deveriam ser os protagonistas, que se completam com suas diferenças pessoais e saberes diversos. Porém, na realidade, estão diante de um processo no qual são designados ao papel de executores de um material pronto, tornam-se meros objetos um do outro no processo de transferência do que está posto.

Diante de tudo o que foi colocado, é possível observar que, tanto nos aspectos gerais do material quanto nos específicos para o conhecimento matemático, se evidenciam elementos que limitam a autonomia do professor e alunos. Entretanto, tal material pode ser útil para auxiliar o trabalho do professor em sala de aula e em outros estudos que dão suporte às atividades diárias, uma vez que, grande parte dos professores, em especial aqueles que atuam nos anos iniciais da Educação Básica, não possuem uma formação integral que lhes permita ter uma participação ativa na elaboração e execução do currículo.

Assim, para ser autônomo, entende-se que o professor precisa dominar certos mecanismos para reflexão conceitual e procedimental que lhe permitirão impor-se diante das situações, em um domínio tão amplo quanto à sala de aula e à escola como um todo, que exigiriam dele uma postura crítica e criativa.

\section{Agradecimentos}

Ao Programa de Pós-Graduação em Educação para a Ciência. 


\section{Referências}

Bogdan, R. C., \& Biklen, S. K. (1994). Investigação qualitativa em educação: Uma introdução à teoria e aos métodos. Porto (Portugal): Porto.

Brasil. (1998). Parâmetros Curriculares Nacionais: $3^{\circ}$ e $4^{\circ}$ ciclos do Ensino Fundamental: Matemática. Brasilia: MEC

Dante, L. R. (1996). Livro Didático de Matemática: uso ou abuso? Em Aberto, 16(69), 83-97.

Fiorentini, D. (1995). Alguns modos de ver e conceber o ensino da matemática no Brasil. Revista Zetetike, 3(4), 1-37.

Freire, P. (1996). Pedagogia da autonomia: saberes necessários à prática educativa. São Paulo: Paz e Terra.

Freire, P. (2016). Pedagogia do oprimido. Rio de Janeiro: Paz e Terra.

Freitag, B., Motta, V. R., \& Costa, W. F. (1987). O estado da arte do livro didático no Brasil. Brasília: REDUC.

Gregolin, M. R. (2006). Foucault e Pêcheux na análise do discurso: diálogos e duelos São Carlos: Claraluz

Hoffmann, J. (2008). Avaliar para promover: as setas do caminho. Porto Alegre: Mediação.

Machado, N. J. (1996) Sobre Livros Didáticos: quatro pontos. Em Aberto, 16(69), 30-38.

R. de C. de F. (2008). Autonomia. In D. R. Streck, E. Redin, \& J. J. Zitkoski (Orgs.), Dicionário Paulo Freire. Belo Horizonte: Autêntica.

Martins, A. M. (2002). Autonomia e Educação: a trajetória de um conceito. Cadernos de Pesquisa, 115, 207-232.

Pozo, J. I., \& Crespo, M. A. G. (2009). A aprendizagem e o ensino de ciências: do conhecimento cotidiano ao conhecimento cientifico. Porto Alegre: Artmed.

São Paulo. Secretaria da Educação. (2013). EMAI: educação matemática nos anos iniciais do ensino fundamental; organização dos trabalhos em sala de aula, material do professor - quarto ano. Centro de Ensino Fundamental dos Anos Iniciais. São Paulo: SE.

São Paulo. Secretaria da Educação. (2014). EMAI: educação matemática nos anos iniciais do ensino fundamental; organização dos trabalhos em sala de aula, material do professor - quarto ano. Centro de Ensino Fundamental dos Anos Iniciais. São Paulo: SE.

São Paulo. Secretaria da Educação. (2015). Ler e Escrever: guia de planejamento e orientações didáticas; professor $-4^{\circ}$ ano. São Paulo: FDE.

Saviani, D. (2002). Educação do senso comum à consciência filosófica. Campinas: Autores Associados.

Saviani, D. (2003). Pedagogia histórico-critica: primeiras aproximações. Campinas: Autores Associados.

Saviani, D. (2005). Escola e democracia. São Paulo: Autores Associados.

Severino, A. T. B, \& Meneghetti, R. C. G. (2014). A criança e a escolar na sociedade contemporânea: uma reflexão sobre os impactos da globalização. Anais do IX Simpósio Pedagógico e Pesquisas em Comunicação (pp. 1-8).

Severino, A. T. B. (2016). O projeto EMAI: uma análise sobre seus pressupostos politicos, filosóficos e pedagógicos e a questão da autonomia. (Dissertação de Mestrado em Educação para a Ciência). Faculdade de Ciências, Universidade Estadual Paulista - Campus Bauru/SP.

Simon, M. (1995). Reconstructing mathematics pedagogy from a constructivist perspective. Journal for Research in Mathematics Education, 26(2), 114-145. 